\title{
El e-Learning en Educación Primaria como consecuencia de la situación generada por el Covid-19: un estudio de caso
}

\section{e-Learning in Primary School due to the situation generated by the Covid- 19: a specific case}

\author{
Rebeca Santa Medina \\ Universidad de Murcia (España) \\ rebeca.santa@um.es
}

Recibido: $12 / 08 / 2020$

Aceptado: $14 / 05 / 2021$

Publicado: 01/06/2021

\section{RESUMEN}

Este trabajo de investigación constituye un estudio de caso, con el que se pretende conocer las implicaciones para el profesorado que ha tenido que pasar de un modelo de enseñanza presencial a una modalidad de e-learning, a raíz de la pandemia del Covid-19, analizando el caso concreto del centro educativo de Primaria Buen Pastor.

Para ello, primero se expone un marco teórico para adentrarnos en el tema objeto de estudio, así como las variables que más tarde analizamos y, a continuación, se muestra la parte empírica, para la que se utilizó una muestra de 20 docentes de Educación Primaria, y se recabó información a través de cuestionarios; así como de entrevistas individuales.

Con todo, el estudio se centró en analizar aspectos como: las herramientas y recursos, así como las estrategias didácticas para el trabajo en red utilizadas por los docentes o su opinión sobre este cambio de modalidad presencial a modalidad online y su punto de vista acerca de ella tras este periodo. Los resultados fueron reveladores, lográndose los objetivos que se perseguían. Con ellos se puso de manifiesto la necesidad de mejorar la alfabetización y la competencia digital de los docentes a pesar de las innumerables herramientas y recursos existentes; el potencial educativo de esta modalidad de enseñanza y el enorme esfuerzo que han tenido que hacer los docentes para adaptarse a ella.

\section{PALABRAS CLAVE}

Educación; e-Learning; Covid-19; educación primaria; docentes.

\section{ABSTRACT}

This research is a case study, which aims to analyze the implications for teachers who have had to change the traditional classroom teaching to e-learning, due to the Covid-19 pandemic, analyzing the specific case of the school of Buen Pastor Primary.

To do this, firstly a theoretical framework is presented to go into the subject of the study, as well as the variables that we later analyzed, and then the empirical part is shown, for which a sample of 20 primary school teachers was taken and information was collected through surveys, as well as through individual interviews.

However, the study focused on analysing aspects such as: the tools and resources, as well as the didactic strategies for working in networks used by the teachers but also their opinion about this change from a face-to-face to an online mode and their point of view about it after this period. The results were revealing, achieving the objectives that were being pursued, and being able to analyze deeply the object of study. With them it was shown how inefficient were the teachers in terms of e-learning despite all the tolos and resources that they had, the high educative potential and the big effort that teachers had to make to adapt themselves to it. 


\section{KEYWORDS}

Education; e-Learning; Covid-19; primary school; teachers.

\section{CITA RECOMENDADA}

Santa, R. (2021). El e-Learning en Educación Primaria como consecuencia de la situación generada por el Covid-19: un estudio de caso. Revista Interuniversitaria de Investigación en Tecnología Educativa, 10, 121-136. https://doi.org/10.6018/riite.439831

\section{Principales aportaciones del artículo y futuras líneas de investigación:}

- Análisis comparativo de experiencias de e-learning en centros públicos y privados como consecuencia del Covid-19.

- Propuesta de actuación para superar la brecha digital en contextos educativos.

- Análisis de las estrategias de e-learning según las edades del alumnado para fomentar un aprendizaje de calidad.

\section{INTRODUCCIÓN Y ESTADO DEL ARTE}

Debido a la actual situación de emergencia sanitaria por el Covid-19, todos los centros educativos de nuestro país se han visto obligados a transformar en muy poco espacio de tiempo la docencia para pasar de un modelo presencial a un modelo online, es decir, a tener que desarrollar acciones de e-learning. El aprendizaje en este tipo de modalidad se produce gracias a la utilización de Internet como sistema de acceso a los contenidos y a las actividades de la formación. Además, la interacción y la comunicación son una parte fundamental en este tipo de formación, tal como expone Salvat (2018).

Así pues, el e-learning se refiere a una modalidad formativa a distancia que se apoya en la red, y que facilita la comunicación entre el profesor y los alumnos, tanto en espacios de comunicación sincrónicos como asincrónicos (Mora-Vicarioli, 2019). Arafeh (2018) añade que, además, posibilitan los intercambios de conocimiento de todos los participantes independientemente de su localización geográfica, hecho que favorece el acceso de gran diversidad de usuarios.

Por otro lado, el Real Decreto-ley 8/2020, de 17 de marzo, de medidas urgentes extraordinarias para hacer frente al impacto económico y social del COVID-19 refleja en su capítulo 1, que el cierre de los colegios afecta al sector educativo irremediablemente. No obstante, uno de los objetivos actuales, tal como recoge el diario digital El diario, es que "el sector educativo sufra las mínimas consecuencias que está generando esta crisis sanitaria" (Manjavacas, 2020, p. 10). En el diario Libertad Digital, Rodríguez (2020) afirma que todos los centros educativos de España intentan que "los alumnos pierdan el menor número de clases posible implantándose en la medida de las capacidades de cada centro programas educativos a distancia" (párr. 3). Así pues, se ha establecido que los contenidos trabajados mediante la enseñanza virtual serán evaluados (González, 2020).

Otro artículo de El País digital pone de manifiesto que la cuarentena que están sobrellevando los centros educativos deja a la luz las deficiencias digitales del sistema, a pesar de los avances tecnológicos que existen hoy día (García, 2020). Y es que es evidente que la competencia digital docente se ha convertido en el siglo XXI en un requisito fundamental dentro del perfil docente (Cela-Ranilla et al. 2017). La competencia digital es definida por la Comisión Europea (2007) como "el uso seguro y crítico de las tecnologías de la sociedad de la información para el trabajo, el ocio y la comunicación." (p.7).

En esta línea, Cabero (2006) asegura que "los problemas hoy no son tecnológicos, sino que se derivan de saber qué hacer y cómo hacerlo, y por qué queremos hacerlo" (p. 8).

$Y$ es que el e-learning transforma completamente la forma en que se plantea el proceso de enseñanza-aprendizaje; y, en consecuencia, los roles del docente y del alumno/a. Como asegura 
Cariaga (2020), en este contexto, "el docente es vital para el éxito de las experiencias formativas en entornos virtuales de aprendizaje, por esta razón es necesario que tome conciencia de su nuevo rol y se forme para desempeñarlo adecuadamente" (p. 9).

Por otro lado, Moreno \& Aziz (2019) afirman sobre el e-learning que "al ofrecer más flexibilidad, se abre la oportunidad para los estudiantes de administrar tiempo, espacio y ritmo de aprendizaje de acuerdo con sus necesidades, permitiéndoles una formación continua sin que pierdan tiempo en desplazamiento" (p. 7). En este punto, Sanmarti \& Márquez (2017) reflexionan sobre el funcionamiento del sistema educativo: "Los alumnos actuales, los llamados nativos digitales, viven en un mundo diferente, con otras reglas y actitudes y con otras necesidades de formación, tanto en contenidos como en métodos" (p. 6). No obstante, esta modalidad requiere como indican Palacios et al. (2019) que el estudiante de e-learning interactúe en los espacios colaborativos con sus compañeros y con los docentes con el fin de que exista la creación y el intercambio de materiales de estudio. Méndez (2013) apuesta por eliminar la jerarquía docentealumno que ha existido tradicionalmente. Como consecuencia, es preciso ajustarse a la heterogeneidad del alumnado y adaptar el aprendizaje a ella (Puerta, 2020).

En este sentido, Cadavieco et al. (2020) sostienen que tiene grandes posibilidades ya que puede plantearse como un apoyo complementario en la etapa de Educación Primaria. En la misma línea, Lara, Villavicencio \& Cedeño (2018) exponen el e-learning es con el tiempo más apreciado y los usuarios muestran un mayor agrado hacia el mismo. Por su parte, Boon et al. (2005) reconocían hace más de diez años que los sistemas de e-learning irían en aumento a lo largo de los años al promover un gran número de oportunidades educativas.

Para Cabero (2013), el mayor beneficio que tiene es la flexibilidad. Una flexibilidad que, como indican Gallego \& Alonso (2007) está relacionada con el "tiempo, contenido, requisitos de admisión, instituciones y recursos e impartición y logística" (p. 215). Sin embargo, el e-learning no está exento de inconvenientes, aunque según Flórez et al. (2017) "se hace evidente que son más las ventajas que se obtienen al implementar este modelo pedagógico..." (p. 97).

Mención aparte se le debe hacer a la brecha digital, definida por Cabero (2004) como la desigualdad de posibilidades que existen para acceder a la información, al conocimiento y a la educación mediante las TIC. En medio de la situación de confinamiento por el Covid-19, se ha hecho aún más evidente esta al intentar continuar con la educación en el país. Tal como manifiesta Lloyd (2020) esta modalidad pone en entredicho la equidad del modelo pues la brecha digital puede darse de tres formas distintas según un informe de la Unión Internacional de Telecomunicaciones (2003):

La de acceso, basada en la diferencia entre las personas que pueden acceder y las que no a las TIC; la de uso, basada en las personas que saben utilizarlas y las que no; y las de la calidad del uso, basada en las diferencias entre los mismos usuarios. (p. 4)

La solución a las brechas digitales no pasa exclusivamente por incorporar tecnologías en la sociedad o en el caso concreto, al ámbito educativo, sino porque los sujetos reciban la formación y la alfabetización digital necesaria para que su puesta en práctica sea significativa. Y es que, como explica Solé (2020), innovación tecnológica no siempre supone una mejora en el contexto educativo.

\section{MÉTODO}

\subsection{Objetivos}

Objetivo general:

Analizar la propuesta metodológica de enseñanza en línea implementada por el centro educativo de Primaria Buen Pastor debido a la situación de confinamiento provocada por el Covid-19, a partir de la percepción de los docentes.

Objetivos específicos:

- Conocer las herramientas y recursos utilizados para llevar a cabo la enseñanza en línea en el centro educativo Buen Pastor. 
- Analizar las estrategias didácticas que han llevado a cabo los docentes del centro Buen Pastor para desarrollar el e-learning.

- Considerar la percepción y valoración de los docentes del centro educativo Buen Pastor sobre el desarrollo de la enseñanza en línea.

- Identificar los puntos fuertes y débiles de la implantación del e-learning.

- Realizar propuestas de mejora ante posibles situaciones futuras en las que tenga que implementarse de nuevo una modalidad de enseñanza en red.

\subsection{Diseño de la investigación}

Se trata de un estudio de caso, ya que se analizará cómo ha sido el proceso de adaptación de la modalidad presencial a la modalidad en línea en un breve periodo de tiempo del centro educativo Buen Pastor, de Murcia; así como las valoraciones que se han formado los docentes sobre tal modalidad, como consecuencia de la actual crisis sanitaria que estamos viviendo debido a la pandemia del Covid-19, la cual ha llevado a todos los españoles a confinarse en sus hogares durante un periodo de aproximadamente dos meses en medio de un estado de alarma.

Este estudio se va a enmarcar dentro de un enfoque mixto y descriptivo. Como se recoge en Madera et al. (2013), un estudio de caso descriptivo ilustra lo que está ocurriendo y por qué, con el propósito de mostrar una realidad.

\subsection{Muestra}

Por otro lado, la muestra de esta investigación está compuesta por 20 docentes que imparten docencia en diferentes materias en la etapa de Educación Primaria en el Colegio privado concertado Buen Pastor, situado en la Plaza de San Agustín de Murcia. La muestra para las entrevistas está conformada por 4 sujetos de la muestra anterior escogidos aleatoriamente.

\subsection{Técnicas e instrumentos de recogida de datos}

Se ha optado por el uso de la encuesta, como técnica, concretamente utilizando el instrumento del cuestionario. Este cuestionario ha sido elaborado en Google Forms y validado por expertos. El cuestionario es anónimo y cuenta con 36 cuestiones, agrupadas en torno a varios aspectos: datos personales; herramientas y recursos; estrategias didácticas para el trabajo en red; y opinión personal.

Por otro lado, para obtener mayor cantidad de información se realizaron entrevistas individuales a cuatro sujetos escogidos aleatoriamente. Se ha optado por una entrevista estructurada y breve, es decir, únicamente consta de cuatro preguntas con un orden decidido previamente, para poder comparar las diferentes respuestas de los docentes. Estas se han diseñado para realizarse por vía telefónica y ser automáticamente grabadas.

\subsection{Tratamiento y análisis de datos}

Se ha llevado a cabo un análisis descriptivo y un análisis de contenido representando los datos mediante Figuras, tablas y porcentajes, lo cual ha permitido establecer relaciones entre ellos y favorecer la extracción de conclusiones y la elaboración de propuestas de mejora.

\section{RESULTADOS}

A continuación, se van a exponer los resultados obtenidos a través de los cuestionarios y las entrevistas. Se va a realizar un análisis descriptivo, lo que va a permitir el estudio detallado de los datos y la información ofrecida por los sujetos de la muestra.

\subsection{Herramientas y recursos para el trabajo en red}

Sobre si los participantes disponen de algún aula virtual, la totalidad de la muestra coincidió en que sí usan un aula virtual para llevar a cabo su docencia de forma online. 
Por otro lado, solo el $10 \%$ afirma que utilizara este entorno antes de la situación actual (Figura 1).

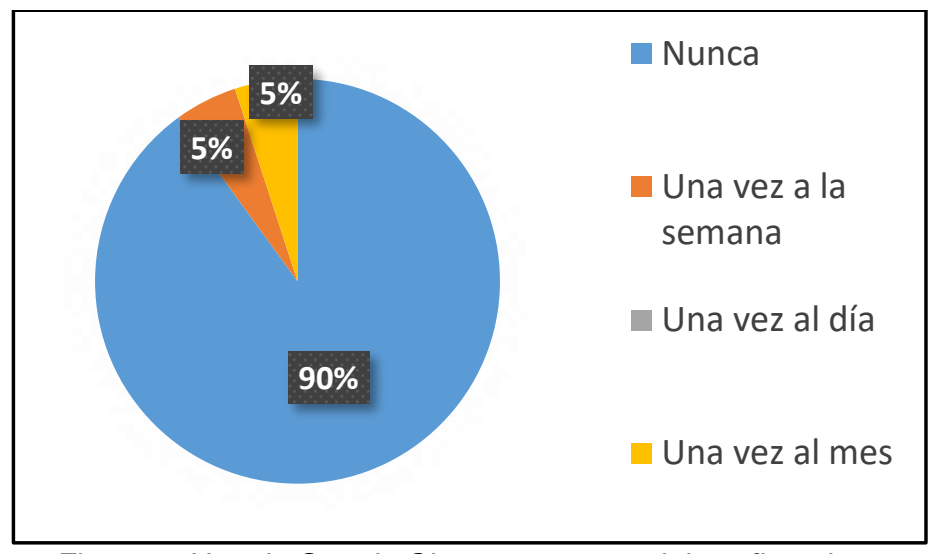

Figura 1. Uso de Google Classroom antes del confinamiento

Respecto a si se le han hecho recomendaciones sobre herramientas y recursos a utilizar, de nuevo el $100 \%$ de los docentes asegura que sí.

En relación a quién ha hecho las recomendaciones, el $95 \%$ de los sujetos coinciden en que fue el equipo directivo; $y$ de estos, el $15 \%$ reconocen que fue por parte de sus compañeros. Solo un $5 \%$ menciona que, además del equipo directivo y sus compañeros, también se encargó el departamento de orientación del centro, el coordinador del Plan de Acción para la Mejora para los Centros Educativos (PAMCE) y la Consejería de Educación y Cultura.

Por otro lado, y fijándonos en el Figura 2, el $47,4 \%$ sí utiliza las herramientas institucionales, mientras que el $52,6 \%$ prefiere el uso de otras.

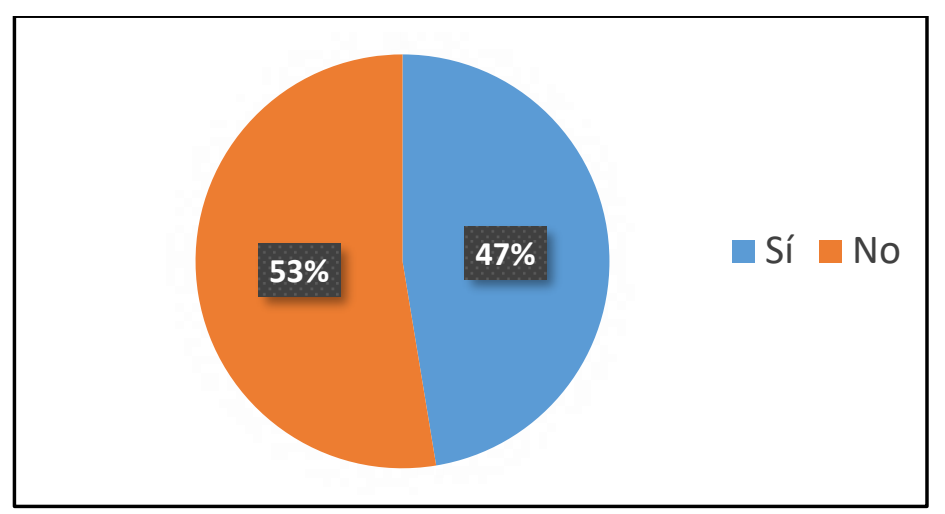

Figura 2. Herramientas no institucionales

Respecto a la frecuencia con la que usan herramientas para la búsqueda y el diseño de recursos educativos digitales, se presentan en la tabla 1. En primer lugar, la que más utiliza el profesorado es Youtube frente a otras como Facebook, Twitter o Instagram. Por otra parte, entre los buscadores destaca Google; mientras que Bing o Yahoo son usados poco o nada. Por último, se analizan las herramientas para elaborar presentaciones. Power Point encabeza la lista; seguida de Google presentaciones. En último puesto estarían Prezi o Genial.ly.

Tabla 1. Herramientas para la búsqueda y el diseño de recursos educativos digitales

$\begin{array}{ccccccc}\text { Redes sociales } & \text { Facebook } & 10 & 1 & 3 & 4 & 2 \\ & \text { Twitter } & 16 & 2 & 1 & 1 & 0 \\ & \text { Instagram } & 8 & 3 & 3 & 4 & 2 \\ & \text { Youtube } & 0 & 3 & 5 & 8 & 4 \\ & \text { Blogs } & 7 & 2 & 5 & 3 & 3 \\ \text { Buscadores } & \text { Otra } & 17 & 0 & 1 & 2 & 0 \\ & \text { Google } & 1 & 2 & 3 & 7 & 7 \\ & \text { Bing } & 20 & 0 & 0 & 0 & 0 \\ & \text { Yahoo } & 19 & 0 & 0 & 0 & 1\end{array}$




\begin{tabular}{c|cccccc}
\multirow{3}{*}{ Presentaciones } & Otra & 20 & 0 & 0 & 0 & 0 \\
\cline { 2 - 7 } & Power Point & 4 & 2 & 3 & 8 & 3 \\
\cline { 2 - 7 } & Prezi & 13 & 4 & 2 & 1 & 0 \\
\cline { 2 - 7 } & Genial.ly & 14 & 0 & 5 & 0 & 1 \\
& Google & 8 & 3 & 5 & 3 & 1 \\
presentaciones & Otra & 15 & & 2 & 2 & 1 \\
\hline
\end{tabular}

Notas: A. Nada, B. Poco, C. A veces, D. Frecuentemente y E. Muy frecuentemente

Sobre la comunicación con los alumnos, las familias y el resto de docentes señalaron las herramientas que usaban para llevarla a cabo y el grado de uso (tabla 2). Sobresale Whatsapp como herramienta de mensajería instantánea. Por último, las herramientas de videoconferencias más utilizadas serían Whatsapp, y, en segundo lugar, Zoom.

Tabla 2. Herramientas para la comunicación entre el personal docente

\begin{tabular}{ccccccc}
\hline \multirow{2}{*}{$\begin{array}{c}\text { Mensajería } \\
\text { instantánea }\end{array}$} & Whatsapp & A & B & C & D & E \\
& & 2 & 1 & 3 & 5 & 9 \\
& Telegram & 16 & 3 & 1 & 0 & 0 \\
& Skype & 16 & 3 & 0 & 1 & 0 \\
& Otra & 11 & 3 & 1 & 1 & 4 \\
\hline \multirow{2}{*}{ Videoconferencia } & Correo electrónico & 2 & 1 & 6 & 4 & 7 \\
& Skype & 15 & 2 & 1 & 1 & 1 \\
& Zoom & 11 & 3 & 1 & 3 & 2 \\
& FreeConferenceCall & 20 & 0 & 0 & 0 & 0 \\
& Whatsapp & 7 & 2 & 3 & 1 & 7 \\
& Otra & 17 & 1 & 0 & 2 & 0 \\
\hline
\end{tabular}

Notas: A.Nada, B. Poco, C. A veces, D. Frecuentemente y E. Muy frecuentemente

Referente al grado de uso de los recursos educativos para la enseñanza de contenidos, se puede apreciar que los docentes emplean recursos escritos (documentos...) con mayor asiduidad, seguidos de los audiovisuales (videos, tutoriales...) y los sonoros (grabaciones de voz, podcast...) (Figura 3).

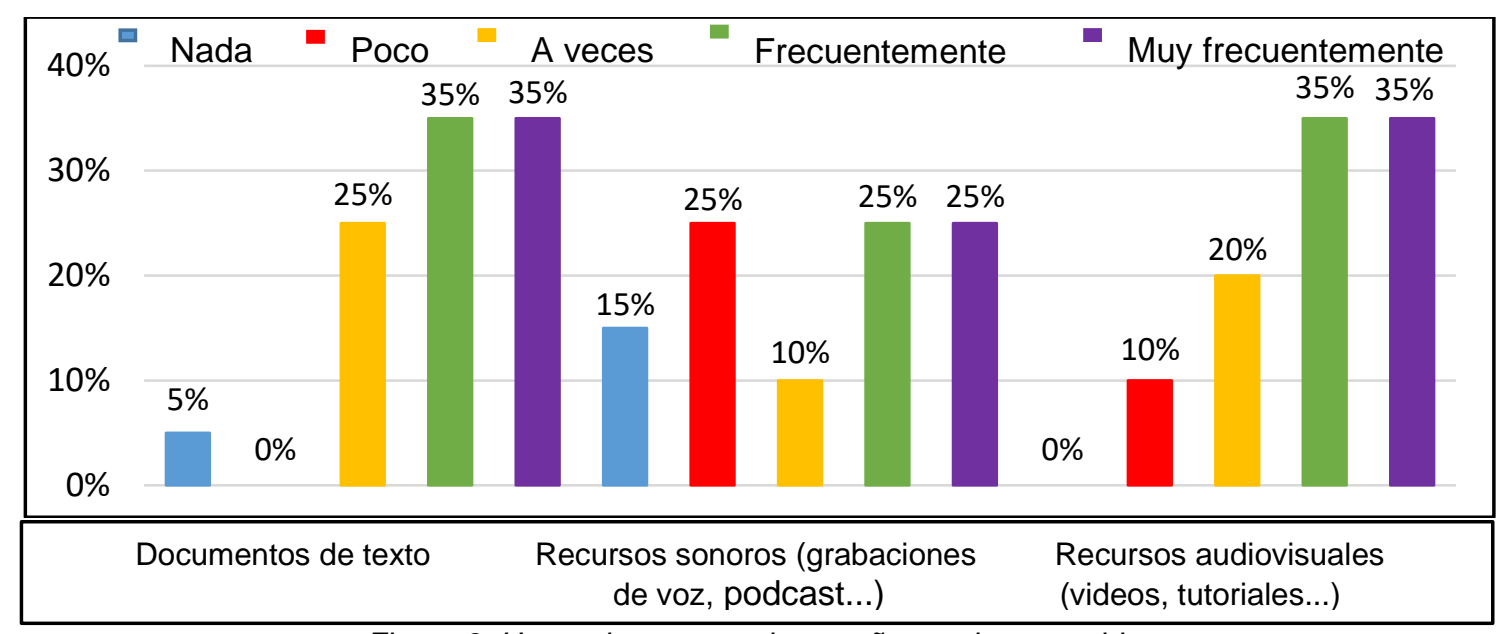

Figura 3. Herramientas para la enseñanza de contenidos

En relación a la metodología aplicada en las videoconferencias, los sujetos aplican metodologías diversas (Figura 4). Cabe subrayar que el $55 \%$ niega el uso de las videoconferencias. Del profesorado que sí las usa, mayoritariamente, señalan que inician la explicación con contenido o actividades; y, posteriormente, se pide la participación de los alumnos (35\%). Aunque en menor medida, también aplican una metodología basada en la interacción constante profesor-alumno o para realizar sesiones de tutoría (15\%). Finalmente, solo un $10 \%$ apunta que se usan como clases magistrales o presentación de trabajos. 


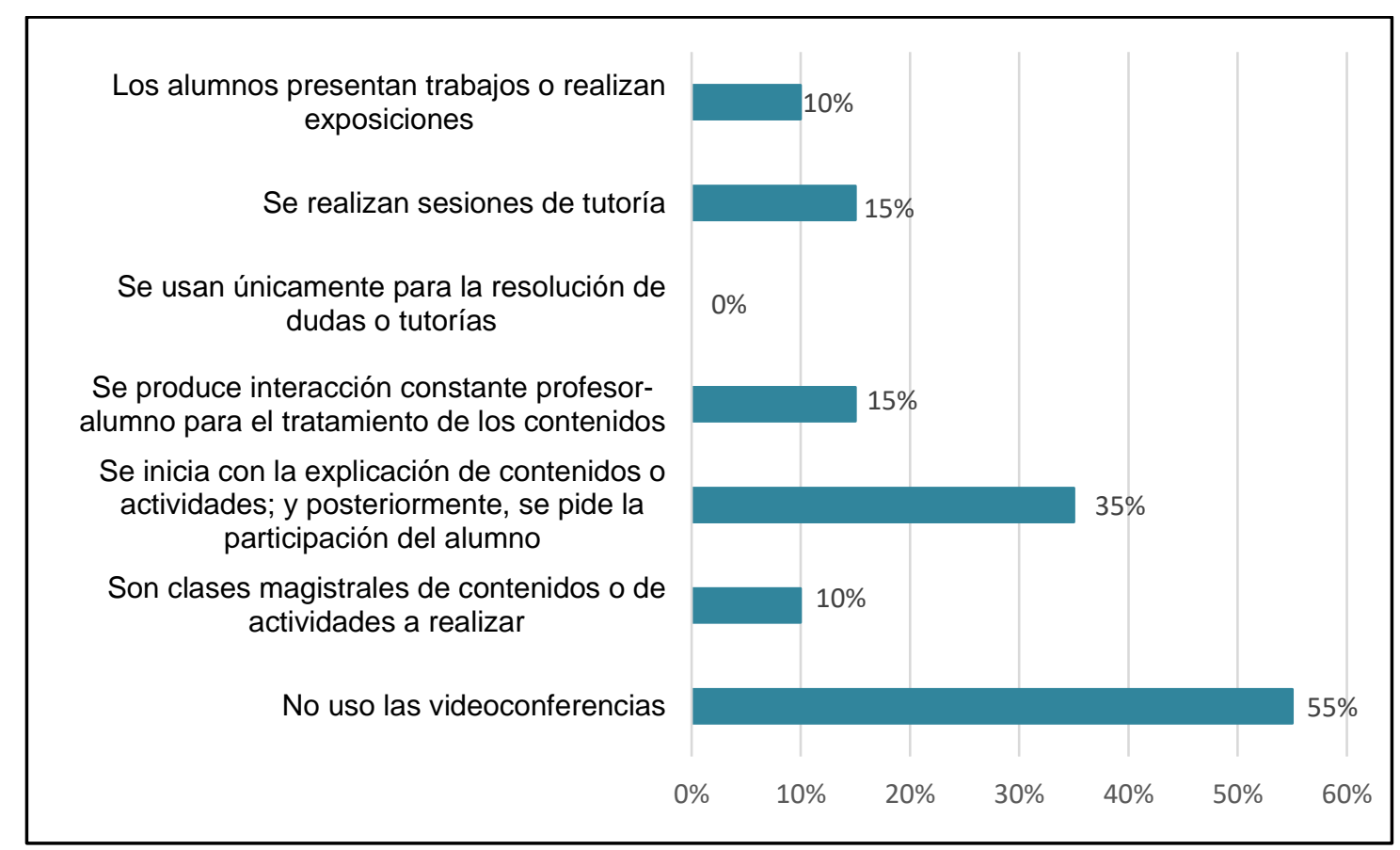

Figura 4. Metodología aplicada en las videoconferencias

Referido a los recursos, casi todos los sujetos utilizan tanto recursos propios como recursos en red (90\%) (Figura 5). Un $10 \%$ sostiene que exclusivamente usa recursos propios. En cuanto al acceso y utilización de recursos libres, el $75 \%$ de los docentes afirma que sí conoce cómo acceder a ellos y usarlos correctamente, mientras que el $25 \%$ sostiene que no (Figura 6).

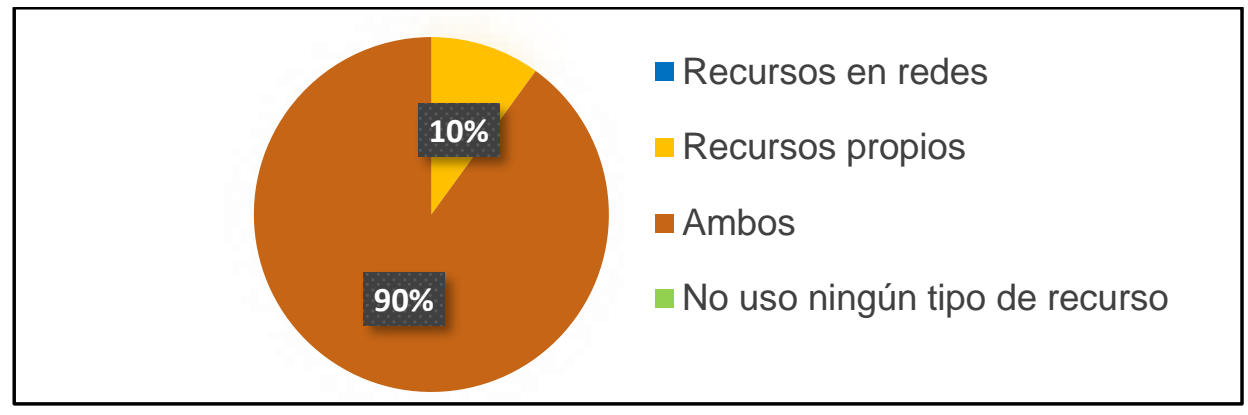

Figura 5. Tipo de recursos

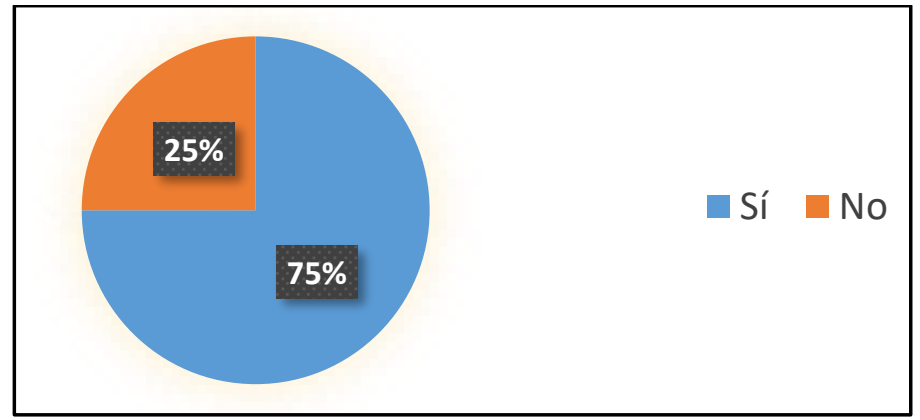

Figura 6. Acceso y uso de recursos libres

\subsection{Estrategias didácticas para el trabajo en red.}

Respecto a si se proporciona al alumnado antes de comenzar una unidad didáctica los objetivos y competencias que deben lograr, el $40 \%$ asegura que sí mientras que el $15 \%$ no lo hace. Cabe subrayar que un $45 \%$ informa al alumnado de ello conforme se van desarrollando las diferentes actividades (Figura 7). 


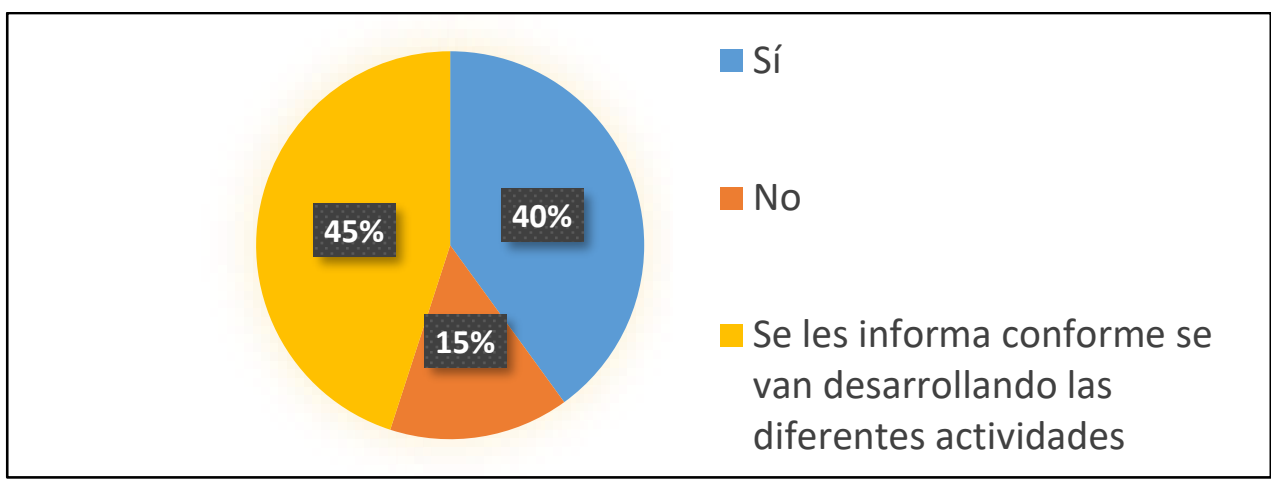

Figura 7. Información proporcionada al alumnado

En cuanto al tipo de actividades que realizan los alumnos en sus casas (Figura 8) casi la totalidad de ellos (90\%) expresa que consisten en la resolución de ejercicios; también tienen especial énfasis las que conllevan la búsqueda de información en red (60\%) o la realización de pruebas de evaluación online (50\%). Por otro lado, aunque en menor grado, también se apoya en la participación en juegos (40\%), la resolución de retos (35\%), la comunicación con los compañeros (35\%) o la publicación de cosas en red (30\%). Solo un pequeño porcentaje (5\%) manifiesta que algunas de las actividades implican participar en debates.

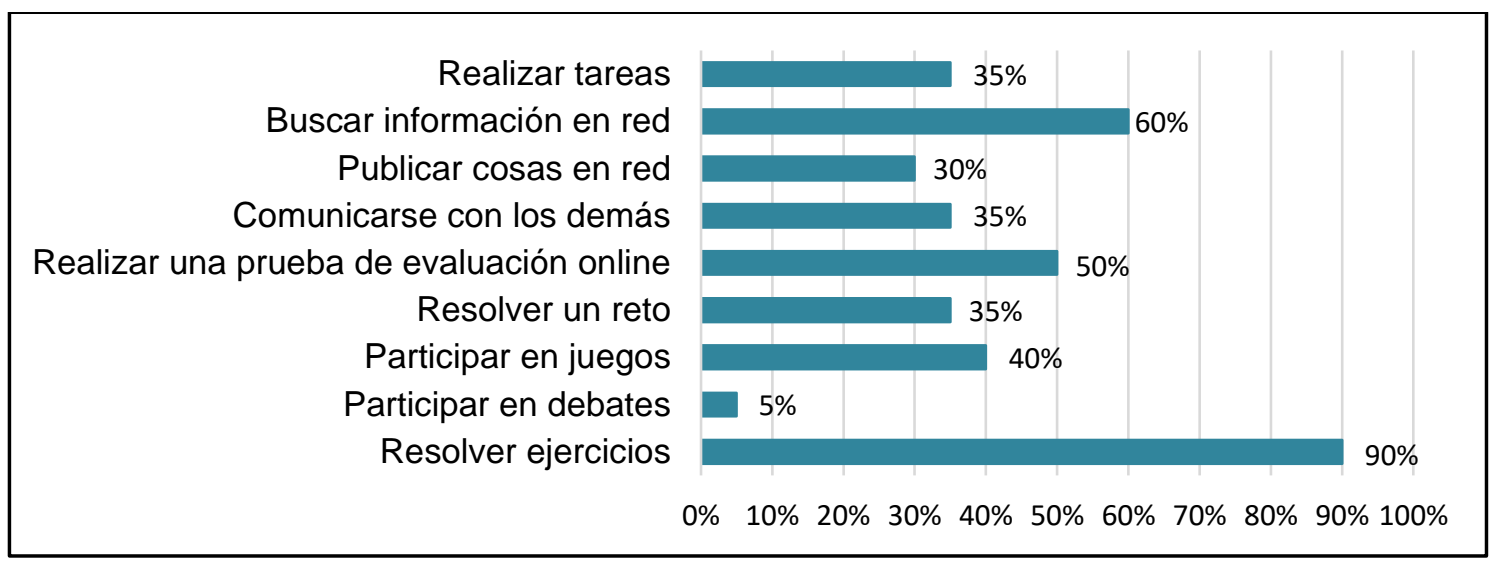

Figura 8. Tipo de actividades

Por otra parte, a la hora de realizar estas actividades, se le plantearon los diferentes agrupamientos posibles: Individuales, por parejas, por equipos y en gran grupo, Así pues, todos los docentes (100\%) han afirmado que las actividades se realizan individualmente. De estos, un $5 \%$ puntualiza que además se agrupan por parejas y otro $5 \%$ en gran grupo (Figura 9 ).

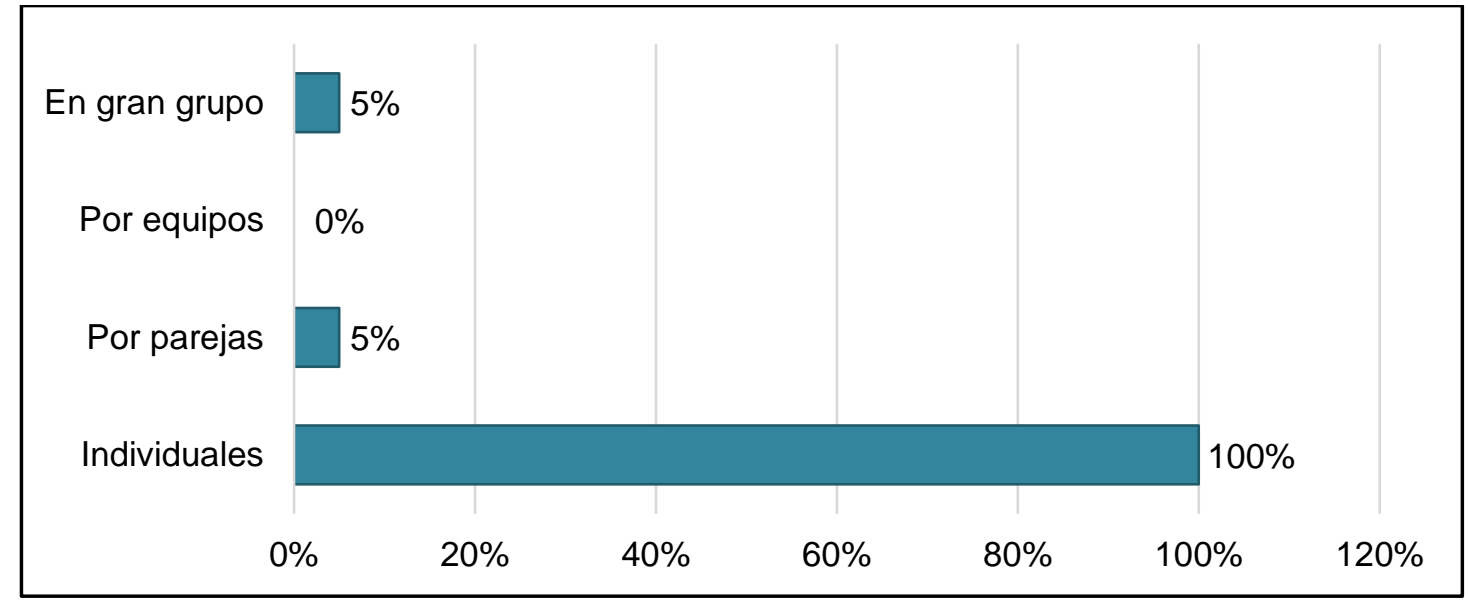

Figura 9. Agrupamientos

Referido a las calificaciones de los alumnos, como muestra el Figura 10, la mayoría sí informa al alumnado sobre las calificaciones que obtienen en las actividades realizadas (60\%). 
Un $30 \%$ declara que solo de algunas actividades. Se sitúan en último lugar aquellos docentes que no hacen saber a sus alumnos sus calificaciones (10\%).

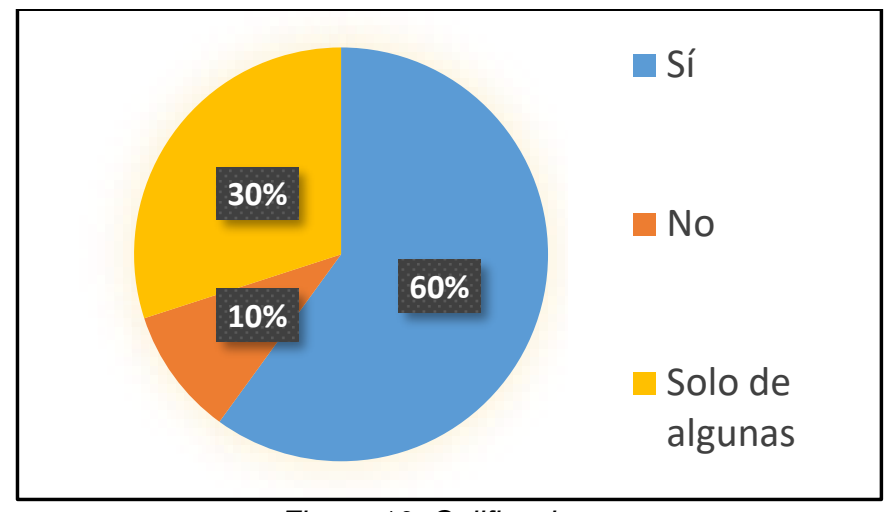

Figura 10. Calificaciones

Relacionado con la retroalimentación en el proceso de trabajo (Figura 11), el $70 \%$ de los docentes dice que sí realiza feedback para informar al alumno de su evolución en el aprendizaje para que este sea consciente de los aspectos que debe reforzar, así como de los logros obtenidos. Únicamente un $5 \%$ no lo efectúa. El resto de los participantes (25\%) expone que solo ofrece retroalimentación al alumnado en determinadas actividades.

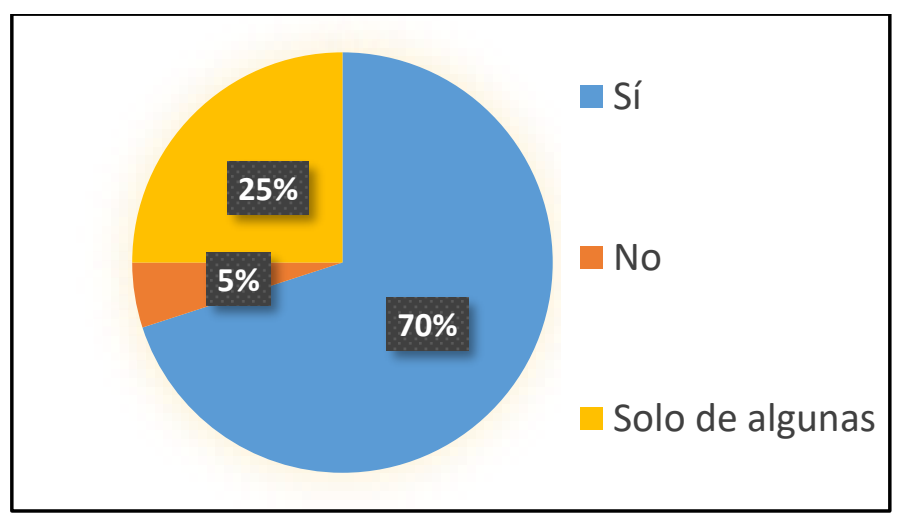

Figura 11. Retroalimentación

En la siguiente cuestión, se intentó ahondar en cómo se proporciona ese feedback a los alumnos, y para ello, se dieron diferentes posibilidades a los participantes (Figura 12). Por mensajes privados es el medio más escogido ( $85 \%)$. En segundo lugar, se encontrarían las videoconferencias individuales con los alumnos (10\%). Un 5\% añadió que, al tener alumnos de seis años, usaba el correo electrónico para ponerse en contacto con los padres.

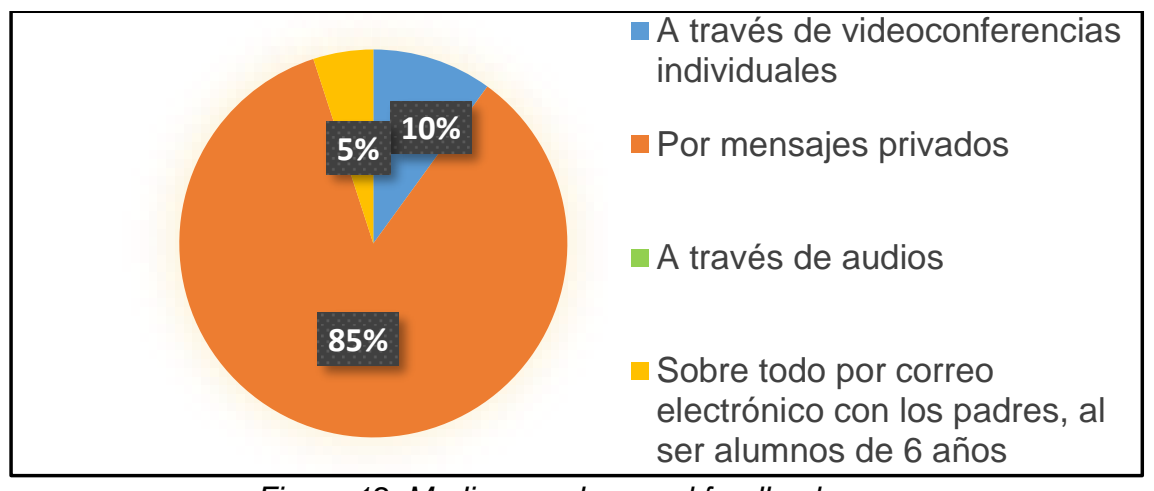

Figura 12. Medios usados en el feedback

Por otra parte, respecto al contacto de los docentes con los alumnos, cabe subrayar que el $70 \%$ de los docentes confiesa que no ha podido establecer contacto con todos ellos y simplemente ha sido un $30 \%$ de docentes los que sí (Figura 13). El número de alumnos ausentes varía desde 1 a 6 (Figura 14). 


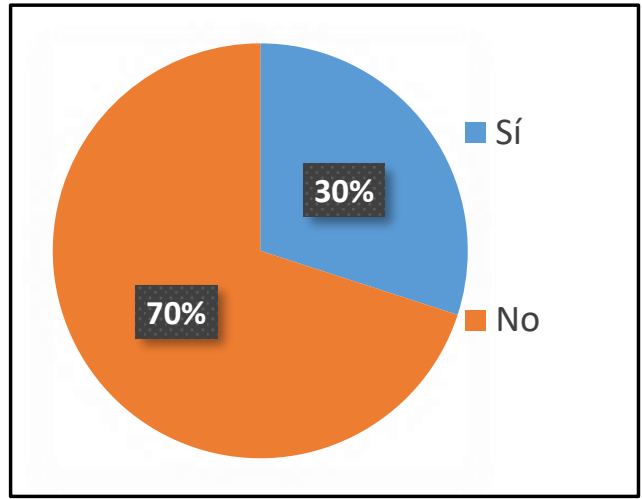

Figura 13. Contacto con los alumnos

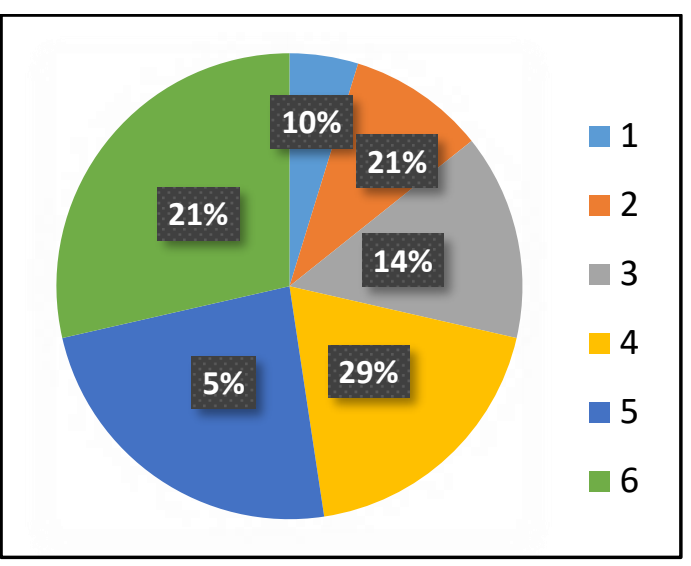

Figura 14. Alumnos ausentes

Ahora bien, preguntando a los participantes cómo consideraban que los alumnos estaban respondiendo a la situación, se obtienen las siguientes respuestas: la mayoría (60 \%) mantiene que, aunque tienen actitudes optimistas y existe colaboración, a veces la situación puede generar incertidumbre y estrés. El $40 \%$ restante señalan que por lo general tienen actitudes optimistas y existe gran colaboración. Ningún participante ha marcado la tercera opción que establece que no existe colaboración y se muestran reticentes (Figura 15).

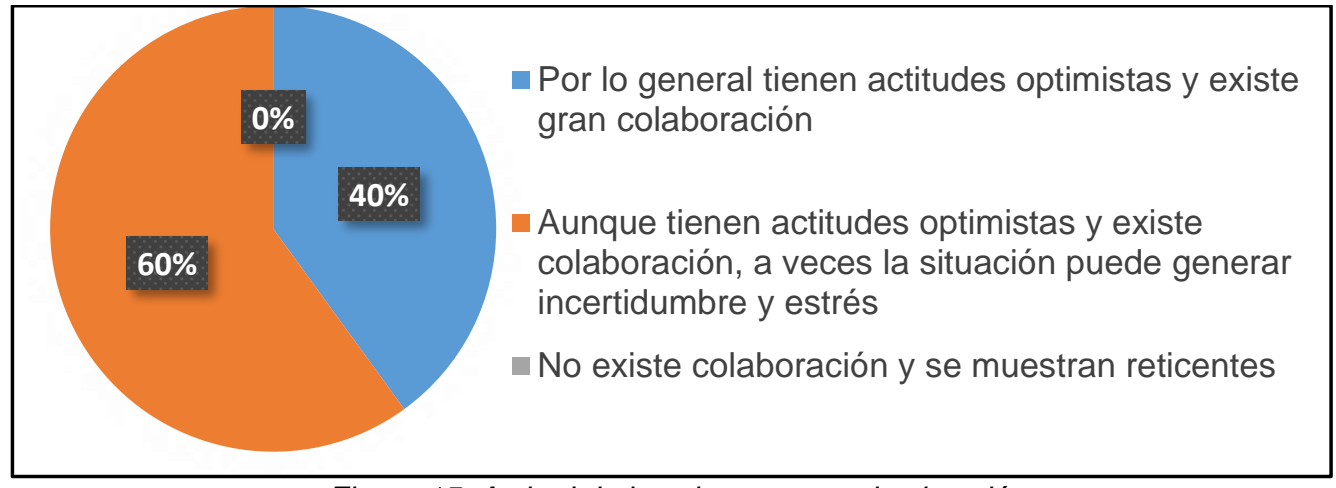

Figura 15. Actitud de los alumnos ante la situación

Sobre los aspectos que los docentes participantes les gustaría recibir formación para mejorar su competencia digital para la enseñanza en red (Figura 16). Así pues, el aspecto que más en falta echan es el diseño de recursos digitales (80\%). En segundo lugar, con un $50 \%$ se sitúa la evaluación del trabajo en red. El uso de herramientas TIC y la utilización de diferentes estrategias de educación en red son dos aspectos en que los docentes coinciden con un 30 \%. En el último puesto estaría la planificación de la educación en red con un 20 \%.

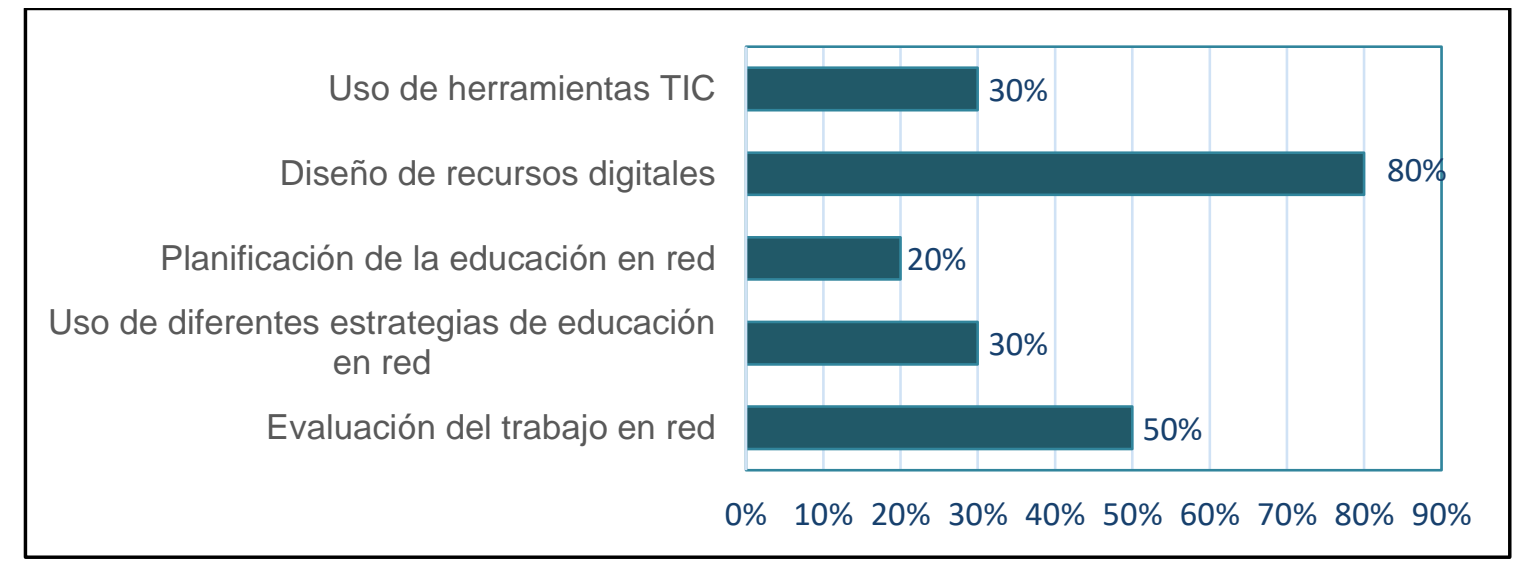

Figura 16. Aspectos para la mejora de la competencia digital 


\subsection{Valoración personal de los docentes}

En cuanto a su grado de satisfacción sobre el desarrollo de la enseñanza virtual, se valora del 1 al 5 , siendo 1 muy malo y 5 excelente. Llama la atención que ningún docente lo ha valorado con un 5 . Un $40 \%$ de los docentes ha puesto un 3 , lo que se traduce en un grado de satisfacción medio. El $30 \%$ un 6, es decir, están satisfechos sin llegar a alcanzar el máximo. Y el $15 \%$ ha valorado con un 2 y el otro $15 \%$ con un 1, por lo que su grado de satisfacción es malo y muy malo, respectivamente (Figura 17).

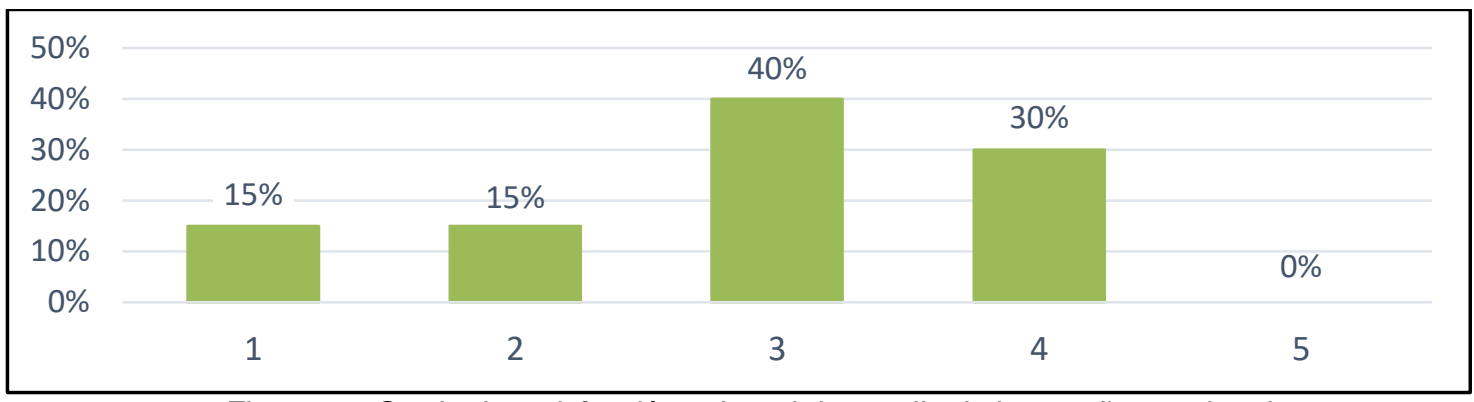

Figura 17. Grado de satisfacción sobre el desarrollo de la enseñanza virtual

Ahora bien, se le preguntó también por el grado de satisfacción sobre la relación con las familias ante esta situación de enseñanza virtual (Figura 18). Al igual que en la cuestión anterior, las respuestas iban del 1 al 5 , siendo 1 muy malo y 5 excelente. Cabe destacar, de nuevo, que nadie calificó esta relación con un 5 . El $40 \%$ puso un 4, por lo que algo menos de la mitad de los participantes están satisfechos con la misma. Un $30 \%$ con un 3, lo que es un grado de satisfacción medio. El resto de los docentes con un 1 o un 2, calificando su satisfacción como mala o muy mala con respecto a este aspecto.

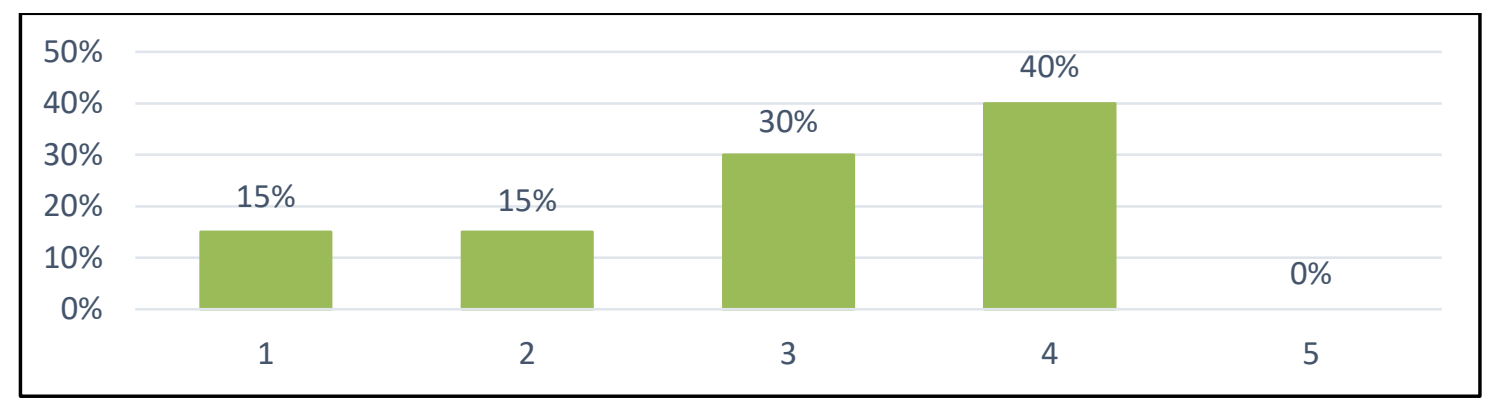

Figura 18. Grado de satisfacción sobre la relación con las familias

El cuestionario finalizaba preguntando a los docentes sobre el grado de interés y motivación percibido de sus alumnos (Figura 19). Para ello, debían calificar de 1 a 5 , siendo 1 muy malo y 5 excelente. Solo en $10 \%$ sostienen que es excelente. La mayoría de los participantes lo puntúan con un $3(45 \%)$ y un 4 (35\%), lo que significa que perciben una motivación alta en su alumnado. Por último, un $5 \%$ piensa que es malo o muy malo, puntuando con un 1 y un 2 el grado de interés y motivación en sus alumnos.

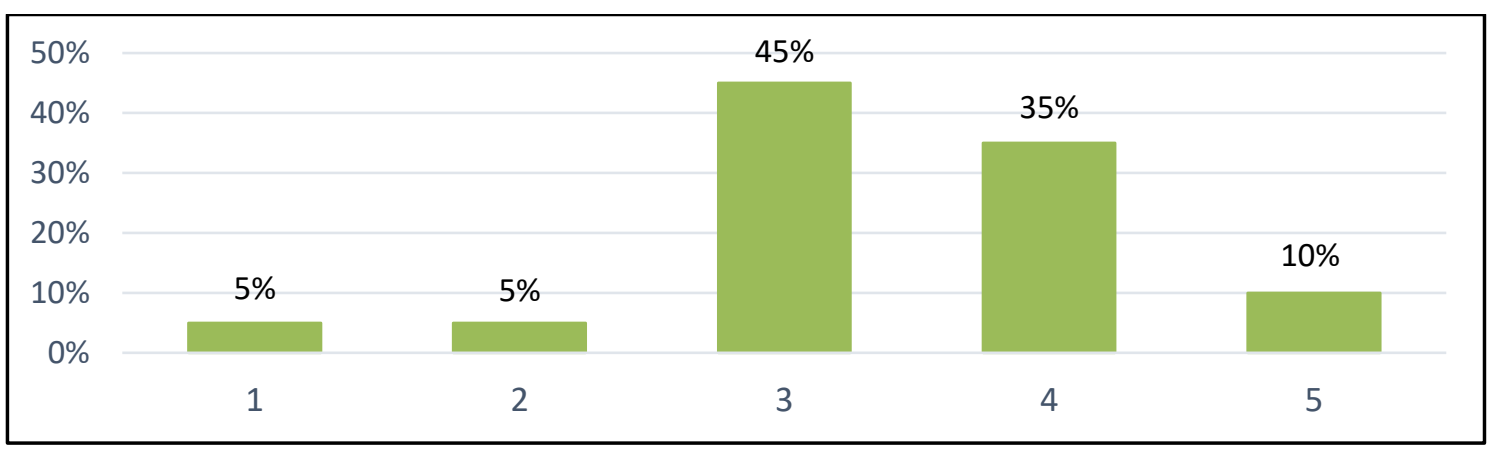

Figura 19. Grado de interés y motivación que percibe el docente de sus alumnos 


\subsection{Análisis de datos de las entrevistas}

La primera cuestión engloba dos preguntas: por una parte, cómo han afrontado los docentes este cambio tan repentino de modalidad presencial a modalidad online. Por otra, si su opinión hacia esta ha cambiado durante este tiempo.

El sujeto 1 y 3 afrontaron en un primer momento esta situación con mayor estrés. El sujeto 1 lo describe como "un cambio brutal", pues explica que "en mi día a día era muy cercano con mis alumnos y de repente me encontré con una máquina de por medio, sin poder verlos, sin poder decirles lo que quisiera porque no sabía cómo iban a reaccionar cómo ocurre en una clase presencial...". Ahora piensa que "no es tan malo, se podría hacer presencial y online, que sería lo ideal". El sujeto 3 aunque mantiene que "en un primer momento muy mal porque veía que no estaba preparada para trabajar telemáticamente (...) poco a poco los alumnos han ido respondiendo muy bien a esta nueva modalidad y veo que todos, en gran medida, nos hemos podido adaptar muy bien a las circunstancias".

El sujeto 2 y 4 tienen puntos de vista más optimistas. El sujeto 2 define lo que ha sucedido como "una sorpresa para todos (...) Aun así, ha sido una oportunidad y un reto nuevo para los docentes de hoy, meternos en el mundo digital, un medio online para llegar a ellos, a nuestros alumnos". Finalmente, el sujeto 4 declara que "este cambio ha sido bastante bueno y lo he aceptado bien", pues las tecnologías forman parte de su vida diaria. Señala que "pensaba que sería más difícil pero ahora, es mucho más fácil, más flexible y los alumnos creo que disfrutan más, pero echan de menos el contacto con los profesores".

En la tercera pregunta se les pidió que hicieran una valoración de su experiencia como docentes online. Hay aquí respuestas diversas.

El sujeto 1 describe su experiencia como "dura, hubo momentos de frustración donde me encontré perdida". Sin embargo, asegura haber hecho "un gran esfuerzo, como todos, para sacar adelante la situación". El sujeto 2 valora su experiencia online positivamente, "en muy poco espacio de tiempo, hemos hecho muchas cosas y hemos aprendido mucho los docentes." Cuenta que para él "ha sido muy importante que las tareas fueran dinámicas, que hubiera una gran diversidad de ejercicios...". Concluye, que "en general, un cambio tan profundo y grande, ha sido positivo.

El sujeto 1 y 2 coinciden con el sujeto 3 en que lo más difícil ha sido la conciliación familiar y se califica con un " 3,5 sobre 5 porque ha sido muy difícil estar las 24 horas del día disponible para los alumnos". El sujeto 4 dice que su valoración es "un 10 porque actualmente, la gente que ha terminado la carrera recientemente como es mi caso, estamos puestos en las redes sociales, en las TIC... por tanto, no representa ningún problema...". Termina asegurando que "hemos dado un gran paso en la educación".

La cuarta y última pregunta era sobre las repercusiones que creían que puede tener la implantación de este modelo de enseñanza en los centros educativos en el futuro.

El sujeto 1 considera que, ante esta situación, se va a implantar de cara al curso que viene y explica que "va a ser otro modelo, otra forma... otra nueva era en la educación. (...) La presencial está muy bien pero online también se trabajará".

El sujeto 2 reconoce que "se ha metido de lleno el mundo digital en nuestras vidas". Sostiene que se podría complementar la presencialidad con una plataforma virtual al mismo tiempo, como son las aulas virtuales: "vamos a convivir con esta forma digital, pero sin perder nuestra esencia, que es la presencialidad, porque somos seres creados para relacionarnos entre nosotros y aprendemos de esta manera, unos con otros".

El sujeto 3 considera que "va a tener una repercusión positiva porque ahora estamos preparados (...) creo que las nuevas tecnologías son muy buenas y gracias a ellas se nos ha podido permitir estar en contacto y seguir con la clase... si hubiera otra pandemia, otro confinamiento, estaremos preparados y lo haremos como hemos hecho porque los alumnos han contestado muy bien (...).

El sujeto 4 apunta que "es relevante que los profesores estén puestos en las TIC para que el curso que viene se puedan hacer más cosas". 
Por tanto, tal como se ha reflejado, todos opinan que esta modalidad ha llegado para quedarse, en mayor o menor grado.

\section{DISCUSIÓN Y CONCLUSIONES}

En este estudio de caso, y partiendo del objetivo general de esta investigación, se ha reflejado en qué ha consistido esta modalidad online o e-learning, la cual ha llevado a los docentes a transformar su práctica educativa e implantar una enseñanza virtual. Así pues, los maestros/as del Buen Pastor han contado con directrices proporcionadas por la Consejería de Educación y Cultura.

Por otra parte, respondiendo al objetivo de conocer las herramientas y recursos utilizados para llevar a cabo la enseñanza en línea en el centro educativo Buen Pastor, se refleja que existen algunas carencias formativas relacionadas con la competencia digital del profesorado, resultando necesaria la formación en materia TIC. Por ejemplo, se observa en el número limitado de herramientas que usan, como es el caso de YouTube o Power Point, que escogen la mayoría de ellos, dejando a un lado otras como Prezi o Genial.ly. Este hecho se agrava cuanto mayor edad tienen los docentes ya que, en su día a día, usan un número menor de herramientas TIC. Otro ejemplo de ello es el uso diario que todos los docentes hacen de la herramienta de Google Classroom como aula virtual a raíz del confinamiento; en contraposición al 10\% de los docentes que únicamente la usaban previamente a esta situación.

Es necesario reconocer la complejidad de la situación que ha provocado que la mayoría de ellos haga un esfuerzo colosal para responder a las necesidades educativas del alumnado. Esto va en la línea de lo que anteriormente se recogía sobre Díaz \& Castro (2017), al explicar que esta adaptación requiere un cambio en su mentalidad, así como la adquisición de un cierto nivel de competencia digital en el uso y manejo de las TIC.

Centrándonos en la Educación Primaria, es vital, como reconocen los docentes de Buen Pastor, que el e-learning provoque que el alumno se sienta protagonista de su proceso de aprendizaje, favoreciendo su capacidad de aprender a aprender poniendo en sus manos estrategias e instrumentos adaptados a su momento evolutivo. Por ello, cada uno de los docentes ha hecho un esfuerzo en adaptar su enseñanza a distancia para que se lograra una educación individualizada y personalizada.

Por otra parte, abordando el objetivo de analizar las estrategias didácticas llevadas a cabo, se pueden nombrar algunas: el aprendizaje basado en juegos, la resolución de problemas planteando tareas a resolver o la investigación individual o por parejas sobre temas diversos, la participación en debates, la búsqueda y publicación de contenido en la web o la realización de pruebas online... Y es que como afirmaban Moneta et al. (2018) en el e-learning el alumno cobra gran protagonismo a través de la autorregulación de su aprendizaje, al mismo tiempo que desarrolla competencias como el pensamiento crítico, la cooperación o la comunicación.

Así, el alumno se ha mantenido en todo su proceso de aprendizaje informado de los objetivos que debía lograr y la retroalimentación posterior. En cuanto a la exposición de los contenidos, se ha realizado a través de recursos multimedia, especialmente vídeos o videoconferencias; recursos visuales como presentaciones de diapositivas; recursos sonoros como podcast o grabaciones de voz y también documentos de texto. Respecto a la comunicación, se daba sobre todo a través del correo electrónico con los padres; de la aplicación de WhatsApp con el resto de personal docente o incluso de videoconferencias con los alumnos.

Cabe destacar que, en esta etapa educativa, y tal y como han manifestado los sujetos participantes, es primordial el papel de los padres o tutores, que son responsables de la educación de sus hijos tal como sostenían Bautista \& Sánchez (2020). Por ello, se puede afirmar que esta modalidad de enseñanza no solo ha ido dirigida a los alumnos sino también a los padres, En general, los padres o tutores de los alumnos/as se han involucrado, comunicándose con los tutores cuando lo precisaban y procurando que sus hijos/as alcanzaran el mejor aprendizaje posible.

Por otra parte, y teniendo en cuenta el objetivo referido a los puntos fuertes y débiles de la implantación del e-learning, así como el que alude a la percepción de los docentes hacia el e- 
learning, se observa que era más negativa en los momentos iniciales, sintiéndose perdidos y sufriendo momentos de total frustración. Es notable el problema que a todos los docentes con hijos les ha afectado: la conciliación familiar. También la proximidad física ha sido un aspecto criticado. A pesar de estos puntos negativos, su opinión hacia el e-learning ha ido cambiando conforme descubrían las oportunidades que ofrece. Todos los docentes han considerado que esta modalidad ha llegado a todos los centros para quedarse, en mayor o menor medida.

Por último, es indudable que existen ciertas deficiencias en los docentes en cuanto a formación en TIC para desarrollar el proceso de enseñanza-aprendizaje. Por ello, respondiendo a otro de los objetivos planteados, se presentan a continuación propuestas de mejora para hacer más efectiva la práctica educativa:

- Cursos de capacitación docente sobre: el diseño de recursos digitales, la evaluación del trabajo en red, el uso de herramientas TIC, la utilización de diferentes estrategias de educación en red para favorecer la formación pedagógica y didáctica o la planificación de la educación en red.

- Recibir más ayuda en torno a aspectos relacionados con: la metodología, la evaluación o la coordinación con los padres.

- Solicitar ayudas para superar la brecha digital, referida a la dificultad de los alumnos de usar la tecnología como un instrumento con fines educativos y no meramente lúdicos.

En definitiva, podemos concluir diciendo que la tecnología educativa de la mano de una buena competencia digital por parte de quien la usa puede suponer una importantísima ayuda como medio de acceder al currículum, como favorecedor de los aprendizajes escolares, como un reforzador didáctico, un medio de individualizar la enseñanza, una herramienta fundamental de trabajo para el docente.

\subsection{Potencialidades y limitaciones de la investigación}

Se pueden reconocer como potencialidades de esta investigación la posibilidad de comprobar que, sin lugar a dudas, las TIC favorecen el proceso de enseñanza-aprendizaje. De igual modo, se ha podido constatar el cambio en la percepción de los docentes hacia ellas conforme aprenden a explotar sus múltiples opciones educativas. Este hecho ha llevado a reconocer la necesidad urgente de la formación docente en materia TIC, la superación de la brecha digital y el adecuado planteamiento del modelo didáctico apoyado en las TIC.

Por el contrario, esta investigación ha contado con una limitación desde el comienzo: la situación singular de pandemia mundial que se está viviendo. Así pues, la falta de información ha sido clara al tratarse de una prueba piloto, teniéndose que recurrir a fuentes relacionadas con la enseñanza en línea aplicada en contextos totalmente diferentes.

\subsection{Futuras líneas de investigación}

Esta investigación podría llegar a ser la base de un futuro proyecto, a través de investigaciones que abarquen comparativamente contextos distintos (centros públicos y concertados/privados; centros de España y centros extranjeros, etc.), muestras más amplias, así como más niveles educativos. Además, se podría estudiar cómo poner fin a la brecha digital; las estrategias más adecuadas en e-learning según las edades del alumnado, así como la explotación de herramientas educativas en red o la creación de las mismas para fomentar un aprendizaje de calidad.

\section{ENLACES}

El cuestionario se ha construido a través de la herramienta Google Forms y está disponible en el siguiente enlace: https://bit.ly/3ftld2a 


\section{REFERENCIAS BIBLIOGRÁFICAS}

Arafeh, A. (2018). Online Learning: Bridging the Cultural Gaps: A Review of Culture and Online Learning: Global perspectives and research. https://bit.ly/3v2V5BA

Bautista, A. \& Sánchez-Lissen, E. (2020). E-learning en 15 días: Retos y renovaciones en la Educación Primaria y Secundaria de la República de Croacia durante la crisis del COVID-19. How have we Introduced distance Learning? Revista española de educación comparada, 36, 181-195. https://doi.org/10.5944/reec.36.2020.27637

Boon, J., Rusman, E., Van Der Klink, M. \& Tattersall, C. (2005). Developing a Critical View on ELearning Trend Reports: Trend Watching or Trend Setting? International Journal of Training and Development, 9(3). https://www.learntechlib.org/p/69793/

Cabero, J, (2004). Reflexiones sobre la brecha digital. En F. Soto, J. Rodríguez (coords), Tecnología, educación y diversidad: retos y realidades de la inclusión digital (pp. 23-42). Consejería de Educación y Cultura.

Cabero, J. (2006). La calidad educativa en el e-Learning: sus bases pedagógicas. Educación Médica, 9, 7-12. https://bit.ly/2SaOt5W

Cabero, J. (2006). Bases pedagógicas del e-learning. RUSC: Revista de Universidad y Sociedad del Conocimiento, 3(1). http://dx.doi.org/10.7238/rusc.v3i1.265

Cabero, J. (2013). La formación virtual en el nuevo entramado 2.0: el e-learning 2.0. Tecnologías y medios para la educación en la e-sociedad, 19, 23-51.

Cadavieco, J. F., Sevillano, M. \& Vázquez-Cano, E. (2020). M-learning en niveles iniciales, rasgos didácticos de las APPS educativas. Campus Virtuales, 9(1), 17-27. https://bit.ly/3wdCkvF

Cariaga, R. (2020). Un marco teórico para analizar el rol docente en entornos de aprendizaje virtualizados. https://bit.ly/3eZgmXv

Cela-Ranilla, J., González, V, Mon, F., Martínez, J. \& Gisbert-Cervera, M. (2017). El docente en la sociedad digital: una propuesta basada en la pedagogía transformativa y en la tecnología avanzada. Profesorado. Revista de Currículum y Formación de Profesorado, 21(1), 403-422. https://bit.ly/3u2iHVP

Comisión Europea. (2007). Competencias clave para el aprendizaje permanente: un marco de referencia europeo. https://bit.ly/33XKriG

Díaz, J. \& Castro, L. (2017). Mentalidad virtual: requisitos para un diseño tutoral en la educación a distancia de la Contabilidad. Cofin Habana, 11(2), 57-68. https://bit.ly/33VTzW5

Flórez, S., Porras, A., Castilla, I. \& Rivera, K. (2017). E-Learning: Rompiendo fronteras. Redes De Ingeniería, 91-100. https://doi.org/10.14483/2248762X.12480

Gallego, D. \& Alonso, C. (2007). La educación a distancia en los nuevos contextos socioeducativos. En J. Cabero (Ed.), Tecnología educativa (pp. 195-218). McGraw-Hill.

García, J (22 marzo, 2020). La odisea de la educación online impuesta por el coronavirus. El País Retina. https://bit.ly/3kraZCd

González, A. (7 abril, 2020). El Consejo Escolar del Estado aprueba medidas para este curso. As. https://bit.ly/32Eko1m

Lara, D., Villavicencio, M., \& Cedeño, E. (2018). E-learning e innovación educativa. Ciencia Digital, 2(1), 75-89. https://doi.org/10.33262/cienciadigital.v2i1.6

Lloyd, M. (2020). Desigualdades educativas y la brecha digital en tiempos de COVID-19. https://bit.ly/3whY5KN

Madera, A., Monasterio, I., Jaraiz, A., Contador, R., Sánchez, J.C. y Varas, R. (2013). Estudio de casos. https://is.gd/MVJZDf 
Manjavacas, F. (17 marzo, 2020). ¿Cómo está afrontando el sector educativo el confinamiento ante el coronavirus? El diario. https://bit.ly/33AgHcd

Méndez, C. (2013). Diseño e implementación de cursos abiertos masivos en línea (MOOC): expectativas y consideraciones prácticas. Revista de Educación a Distancia, 39. https://bit.ly/349Ft3L

Moneta, A., González, M., Tofful, C., Arrieta, M. \& Britos, V. (2018). Hacia un modelo estructural del e-learning. https://bit.ly/3fvpeTz

Mora-Vicarioli, F. (2019). Estado del arte de la evaluación de los aprendizajes en la modalidad del e-learning desde la perspectiva de evaluar para aprender: precisiones conceptuales. Revista Electrónica Calidad en la Educación Superior, 10(1), 58-95. https://doi.org/10.22458/caes.v10i1.2453

Moreno, A., \& Aziz, C. (2019). Formación continua online: Aprendizajes para el futuro de los líderes educativos. https://bit.ly/3fyjzMR

Palacios, M., Reyes, L. \& Asdrúbal, L. (2019). Sistema para la integración de grupos de trabajo para e-learning basado en actividad de los usuarios en la red social Twitter [Trabajo Fin de Grado, Instituto tecnológico de Orizaba], Repositorio Digital TecNM. https://bit.ly/3bCwhZv

Puerta, M. J. (2020). El docente multitarea en L2. Enseñanza intergeneracional, intercultural y multimodal. Foro de profesores de E/LE, 16, 143. https://bit.ly/3tUEhvv

Real Decreto-ley 8/2020, de 17 de marzo, de medidas urgentes extraordinarias para hacer frente al impacto económico y social del COVID-19. https://bit.ly/3yhUsXb

Rodríguez, M. (11 marzo, 2020). Coronavirus y educación: ¿se recuperarán las clases?, ¿afectará a la EvAU? Libertad digital. https://bit.ly/3v4FbqG

Salvat, B. G. (2018). La evolución del e-learning: del aula virtual a la red. Revista lberoamericana de Educación a Distancia, 21(2), 69-82. https://doi.org/10.5944/ried.21.2.20577

Sanmarti, N. \& Márquez, C. (2017). Aprendizaje de las ciencias basado en proyectos: del contexto a la acción. Apice, 1(1), 3-16. https://bit.ly/3bxTNHh

Solé, J. (2020). El cambio educativo ante la innovación tecnológica, la pedagogía de las competencias y el discurso de la educación emocional. Una mirada crítica. Teoría de la Educación, 32(1), 101-121. https://doi.org/10.14201/teri.20945

Unión Internacional de Telecomunicaciones (2003). Digital Access Index: World's First Global ICT Ranking. Education and Affordability Key to Boosting New Technology Adoption. https://bit.ly/3yjr3M6

\section{INFORMACIÓN SOBRE LOS AUTORES}

\section{Rebeca Santa Medina \\ Universidad de Murcia}

Graduada en Educación Primaria con mención en Recursos para la Escuela y el Tiempo Libre, por la Universidad de Murcia (2014/2018). Actualmente cursando el Máster Interuniversitario en Tecnología Educativa E-learning y Gestión del Conocimiento en la Universidad de Murcia (UM). Investigación realizada sobre el e-learning como modalidad de enseñanza en la Educación Primaria a causa del Covid-19.

Los textos publicados en esta revista están sujetos a una licencia de Reconocimiento 4.0 España de Creative Commons. Puede copiarlos, distribuirlos, comunicarlos públicamente y hacer obras derivadas siempre que reconozca los créditos de las obras (autoría, nombre de la revista, institución editora) de la manera especificada por los autores o por la revista. La licencia completa se puede consultar en:Licencia Creative Commons Atribución-NoComercial-Compartir por igual 4.0 Internacional. 